Review

\title{
The role of melatonin in the treatment of type 2 diabetes mellitus and Alzheimer's disease
}

\author{
Shengnan Shen ${ }^{1,2^{*}}$, Qiwen Liao ${ }^{*}$, Yin Kwan Wong ${ }^{4}$, Xiao Chen ${ }^{5}$, Chuanbin Yang ${ }^{6}$, Chengchao Xu $^{1}$, Jichao \\ Sun $^{6,7 凶}$, Jigang Wang $1,8,9,10^{\bowtie}$ \\ 1. Artemisinin Research Center, and Institute of Chinese Materia Medica, China Academy of Chinese Medical Sciences, Beijing, China. \\ 2. State Key Laboratory of Quality Research in Chinese Medicine, Institute of Chinese Medcal Sciences, University of Macau, Taipa, Macau, China. \\ 3. School of Life and Health Sciences, The Chinese University of Hong Kong, Shenzhen, Guangdong, China. \\ 4. Department of Pharmacology, Yong Loo Lin School of Medicine, National University of Singapore, Singapore 117600, Singapore. \\ 5. School of Biopharmacy, China Pharmaceutical University, Nanjing 211198, China \\ 6. Department of Geriatrics, Shenzhen People's Hospital (The Second Clinical Medical College, Jinan University; The First Affiliated Hospital, Southern \\ University of Science and Technology), Shenzhen, China. \\ 7. Shenzhen Mental Health Centre, Shenzhen Kangning Hospital, Shenzhen, China. \\ 8. Guangdong Provincial Key Laboratory of New Drug Screening, School of Pharmaceutical Sciences, Southern Medical University, Guangzhou, China. \\ 9. Key Laboratory of Prevention and Treatment of Cardiovascular and Cerebrovascular Diseases, Ministry of Education, Gannan Medical University, \\ Ganzhou, China. \\ 10. Central People's Hospital of Zhanjiang, Zhanjiang, Guangdong, China. \\ * These authors contributed equally. \\ $\triangle$ Corresponding authors: Email: jgwang@icmm.ac.cn or sunjichao@mail.sustech.edu.cn
}

(C) The author(s). This is an open access article distributed under the terms of the Creative Commons Attribution License (https://creativecommons.org/licenses/by/4.0/). See http://ivyspring.com/terms for full terms and conditions.

Received: 2021.09.07; Accepted: 2021.10.21; Published: 2022.01.01

\begin{abstract}
In type 2 diabetes mellitus (T2DM) and its related disorders like obesity, the abnormal protein processing, oxidative stress and proinflammatory cytokines will drive the activation of inflammatory pathways, leading to low-grade chronic inflammation and insulin resistance (IR) in the periphery and impaired neuronal insulin signaling in the brain. Studies have shown that such inflammation and impaired insulin signaling contribute to the development of Alzheimer's disease (AD). Therefore, new therapeutic strategies are needed for the treatment of T2DM and T2DM-linked AD. Melatonin is primarily known for its circadian role which conveys message of darkness and induces night-state physiological functions. Besides rhythm-related effects, melatonin has anti-inflammatory and antioxidant properties. Melatonin levels are downregulated in metabolic disorders with IR, and activation of melatonin signaling delays disease progression. The aim of this Review is to highlight the therapeutic potentials of melatonin in preventing the acceleration of $A D$ in T2DM individuals through its therapeutic mechanisms, including antioxidative effects, anti-inflammatory effects, restoring mitochondrial function and insulin sensitivity.
\end{abstract}

Key words: Melatonin; Type 2 diabetes; Alzheimer's disease; Mitochondria; Anti-inflammatory; Insulin resistance

\section{Introduction}

Metabolic disorders, including type 2 diabetes mellitus (T2DM) and obesity-related insulin resistance (IR) accelerate not only cerebrovascular disease and stroke, but also neurodegenerative diseases, especially the development of Alzheimer's disease $(\mathrm{AD})[1,2]$. It is generally accepted that brain IR leads to failure of response to insulin, eventually causing impairments in metabolic and immune functions. Globally, the epidemics of T2DM and AD are increasing, which bring huge costs in economic burden and human life suffering. Hence, it is necessary to develop preventive or disease-modifying agents based on pathological studies of these diseases. The link between T2DM and AD was shown in Figure 1.

Exogenous melatonin has been investigated as a therapeutic agent for many diseases. Notably, the metabolic effects of melatonin in T2DM and obesity have been of interest $[3,4]$. Also, decreased melatonin production and secretion were shown to be related to 
neurological diseases like schizophrenia, stroke, and $\mathrm{AD}[5,6]$. Besides the various physiological roles of melatonin in endocrine and neurological disorders, numerous actions of melatonin have been proven safe in animal models and human beings at a wide-range dosage window. In this review, the therapeutic efficacy of melatonin in reversing IR on T2DM and $\mathrm{AD}$ will be discussed. Moreover, whether melatonin will be beneficial in halting AD progression in T2DM individuals will be summarized. We hope this review will highlight the therapeutic potentials of melatonin for the treatment of T2DM and AD.

T2DM is one of the risk factors for AD onset. The underlying mechanism is suggested to be the dysfunction of insulin signaling [7]. Insulin resistance was also observed in AD patients that did not have T2DM [8]. The insulin receptor is responsible in enhancing glucose uptake, mitochondrial function and replacement, anti-apoptosis, and autophagy via MAPK, AKT signaling pathways, and Nrf2 activation against oxidative stress [9-11]. Therefore, Insulin is not only a hormone for glucose homeostasis, but also a key regulator in neuronal generation, repair, and functions [12].

\section{Association between pathogenesis of T2DM and AD}

High levels of blood glucose elevate the risk of dementia in both diabetic and nondiabetic individuals by rates of $40 \%$ and $10 \%$, respectively [13]. Obesity, a T2DM-related disease, has also been shown to increase the risk of $\mathrm{AD}$ and dementia in the elderly population [14] In the following section, the pathological links between T2DM and AD, especially the mechanisms of the development of T2DM to AD including inflammation and defective insulin signaling, will be summarized.

\section{Inflammation}

Chronic inflammation is thought to participate in the pathogenesis of T2DM. In metabolic disorder like T2DM, the adipose-resident macrophages are polarized towards a pro-inflammatory (M1-polarized) phenotype, increasing the expression of inflammatory mediators, including interleukin-6 (IL-6), tumor necrosis factor- $\alpha$ (TNF- $\alpha$ ), and IL-1 $\beta$. These proinflammatory cytokines can cross the blood brain barrier, causing brain insulin resistance [15]. Notably, inflammation also underlines hypothalamic dysfunction in obesity [16]. It was found that insulin receptor substrate 1 (IRS-1) inhibition by amyloid $\beta$ $(\mathrm{A} \beta)$ oligomers, a pathological hallmark of $\mathrm{AD}$, via TNF- $\alpha / J N K$ activation showed impaired brain insulin signaling in $\mathrm{AD}$ and promoted proinflammatory signaling [17]. The IkB kinase (IKK), a stress kinase, was found to be activated by TNF- $\alpha$ in peripheral metabolic tissues and AD brains [18]. Recently, a multiplexed immunoassay revealed neuroinflammatory changes along with diabetic symptoms using different models, including APPswe/PS1dE9 (APP/PS1) mice with high-fat diet (HFD), APP/PS1 with $\mathrm{db} / \mathrm{db}$ mice, and APP/PS1 with STZ, which found that the levels of both chemokines like MIP-1a, MIP-1 $\beta$, and MCP-1, and proinflammatory cytokines like Il-1a, Il-3, and IFN- $\gamma$ were upregulated in these AD pathology-associated T2DM models [19]. The broad range of cytokines promoted neuronal injury, BBB breakdown, and brain insulin resistance. The peripheral mediators including cytokines and adipokines may link the peripheral and central inflammatory, as shown in Figure 2, so the approaches which combat these dysregulated signaling events may have the potential to treat T2DM and AD.

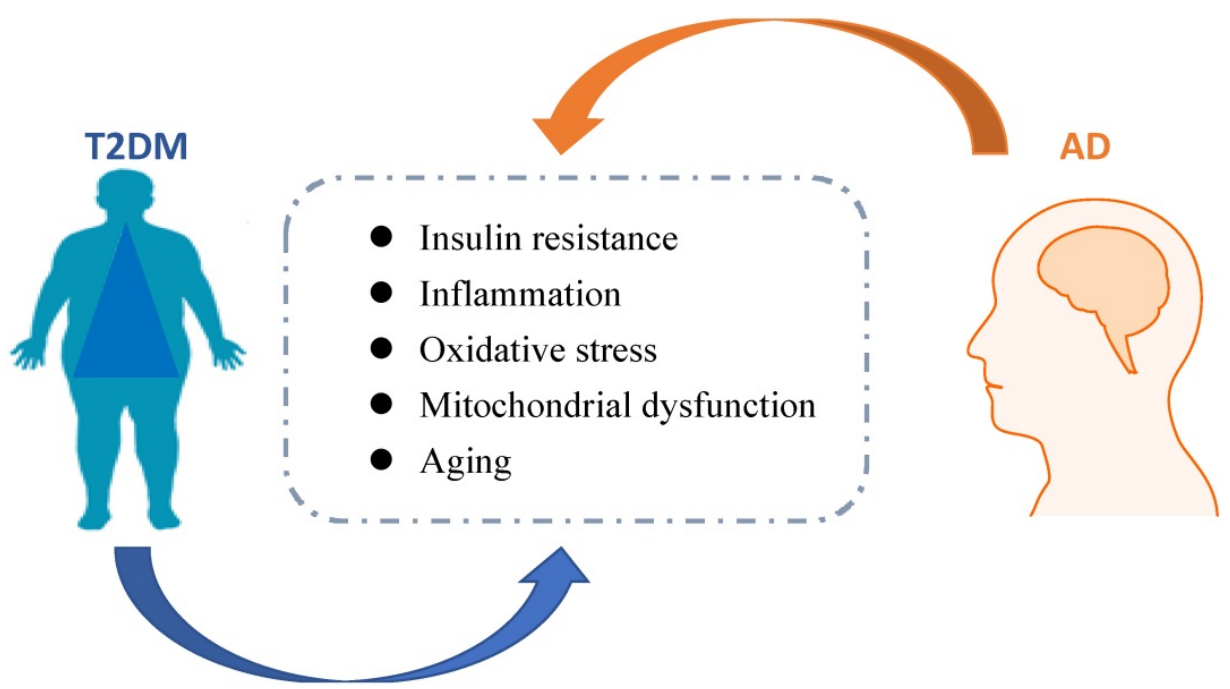

Figure 1. The link between AD and T2DM. Pathological mechanisms associated with T2DM might accelerate AD progression. Insulin resistance, inflammation, oxidative stress, michondrial dysfunction, and aging are related to diabetes, which possibly contributed to AD development. 


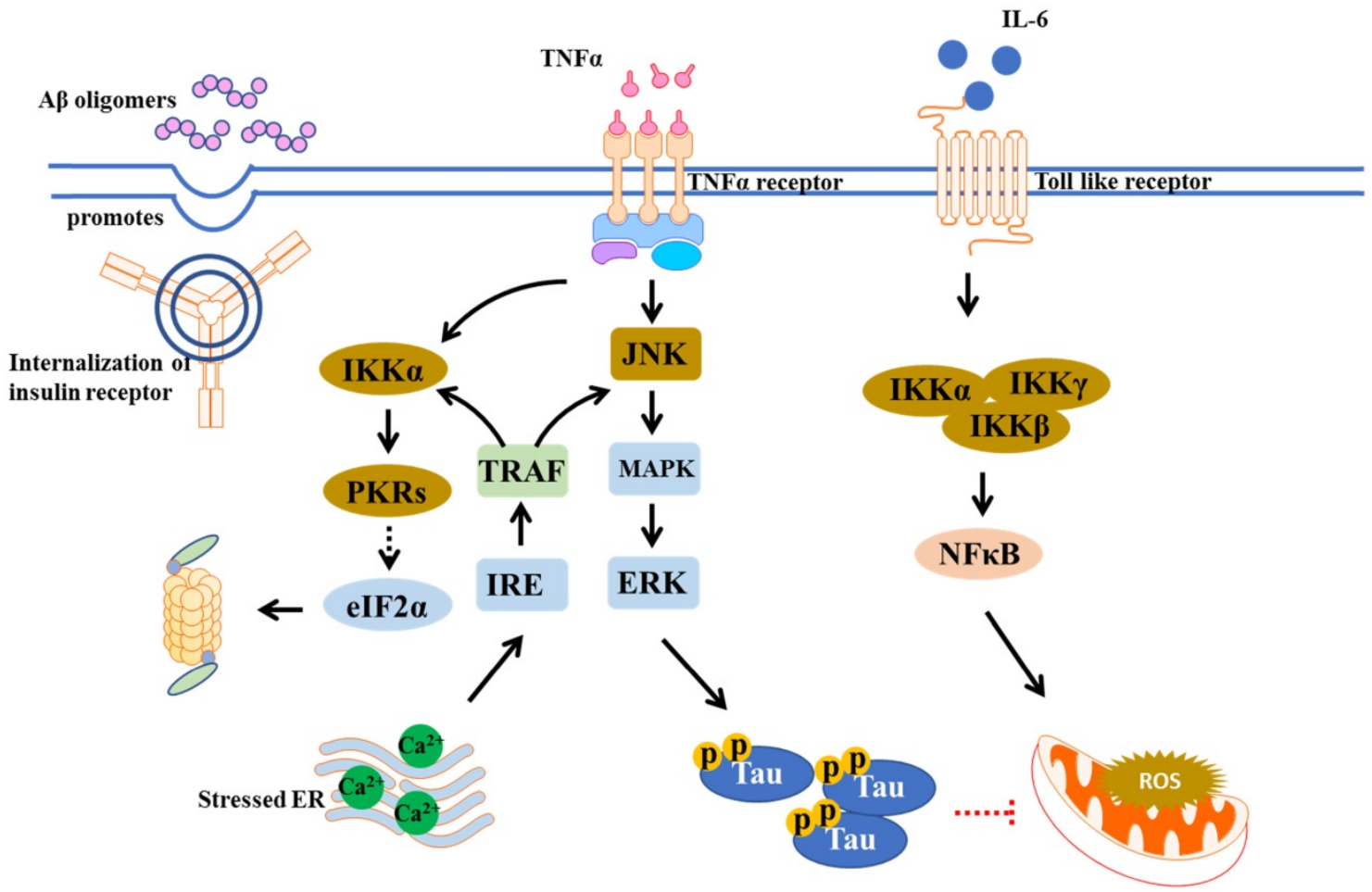

Figure 2. Overlap inflammation signaling in AD and T2DM. Microglial activation by A $\beta$ oligomers stimulates production/release of TNF- $\alpha$. TNF- $\alpha$ receptor activation promotes stress kinases including JNK, IKK, and PKRs, which in turn blocks the insulin actions.

Neuroinflammation can be triggered by $A \beta$ deposition and tau hyperphosphorylation [20]. It is involved in microglia activation that primarily targets $\mathrm{A} \beta$ phagocytosis. However, sustained microglial activation leads to accumulation of inflammatory mediators and danger-associated molecular patterns (DAMPs), limiting $A \beta$ clearance, resulting in more plaque accumulation and neuronal dysfunction [21, 22]. Inflammation is suggested to be linked to insulin resistance. Insulin resistance can increase levels of advanced glycation end products (AGEs), which cause upregulation of GSK-3 $\beta$ and activation of NF-kB pathway, thus induces ROS and pro-inflammatory cytokine production [23]. These pro-inflammatory cytokines were observed to inhibit phagocytosis thus enhance $A \beta$ accumulation, while NF-KB signaling pathway activates AGEs binding to in turn increase $A \beta$ expression [24, 25].

\section{Defective insulin signaling}

In both human and rodents, high dietary fat intake could increase oxidative stress and ROS production in skeletal muscles, leading to the development of peripheral IR in T2DM [26]. IR is a hallmark of obesity and T2DM, which is also found in the brains of AD patients [1]. Indeed, many studies suggest that the incidence of $\mathrm{AD}$ is higher in obesity and T2DM patients. In obesity and diabetes, the signaling pathway IR/insulin-like growth factor (IGF) was altered [27]. Insulin-degrading enzyme (IDE) is important for insulin and $A \beta$ clearance. IR can lead to hyperinsulinemia, which saturates IDE for insulin and $A \beta$ degradation. Thus, dysfunction in $A \beta$ degradation caused by IR increases risk of AD onset [28]. In AD brains, over-activation of N-methyl-D-aspartate (NMDA) receptors by $A \beta$ oligomers is a key factor resulting in excessive ROS production, followed by excessive $\mathrm{Ca}^{2+}$-induced mitochondrial dysfunction. Brain insulin signaling acts to block $A \beta$ oligomers-induced neuronal oxidative stress, via activation of AKT and prevention of aberrant NMDA receptor signaling $[29,30]$. Moreover, $A \beta$ oligomers desensitize the insulin receptors from plasma membrane in cultured hippocampal neurons, reducing tyrosine kinase activity of the insulin receptor protein, which is important for tyrosine phosphorylation and subsequent activation of insulin receptor substrates (IRS), like mTORC1, PI3K, and Akt [31]. The IR in the brain is shown in Figure 3. Therefore, the agents which can stimulate brain insulin signaling may facilitate neuroprotection in AD and preserve normal brain functions.

Insulin signaling is essential in proper brain function like memory formation. Impaired brain insulin signaling can cause cognitive decline in human and animal models. Post-mortem AD displayed hyperphosphorylated Tau-containing neurons and insulin accumulated tauopathies [32]. Conversely, insulin resistance can in turn induce Tau hyperphosphorylation. Compared to normal 
individuals, higher levels of phosphorylated Tau in cerebrospinal fluid (CSF) were observed in cognitive dysfunction subjects due to systemic insulin resistance [33]. A mechanism underlying this phenomenon involves a Tau kinase, the glycogen synthase kinases $3 \beta$ (GSK3 $\beta$ ), regulated by insulin through AKT pathway [34]. Insulin resistance due to chronic exposure of high insulin levels of neurons, or eventual decrease in insulin levels in brain, reduces AKT phosphorylation, leading to an activation of GSK3 $\beta$, inhibition of Tau phosphatases, ultimately Tau phosphorylation $[35,36]$.

\section{Physiological roles of melatonin}

Melatonin is essential in the management of circadian rhythms of healthy metabolism. There are two specific receptors of melatonin, MT1 and MT2, encoded by MTRN1A and MTRN1B, respectively [37]. When melatonin binds to MT1 and MT2, the subunits $\alpha$ and $\beta / \gamma$ dissociate to trigger downstream signaling pathways including adenylyl cyclase (AC), phospholipase C (PLC), and phospholipase A2 (PLA2) [38]. It has been shown that disturbance of melatonin signaling is implicated in development of T2DM raised by IR [39-42]. Impairment of sleep and circadian systems are involved in T2DM and obesity etiology, suggesting the prevalence of metabolic disorders in the individuals with irregular lifestyle like light at night, night-shift working, unusual meal timing, are increasing $[43,44]$. Thus, a combination of the chronobiotic and cytoprotective effects of melatonin may be an innovative strategy in T2DM treatment. The beneficial effects of melatonin on different models of T2DM are shown in Table 1.

\section{Satiety and appetite regulation}

Melatonin is important for the secretion of metabolic hormones leptin and ghrelin to regulate satiery and appetite. Leptin is a regulator for the anorexigenic response. In hypothalamic neurons, it manages energy homeostasis via activation of leptin receptors (LepR), followed by activation of Janus kinase2 (JAK2) and signal transducer and activator of transcription 3 (STAT3) pathways [63, 64]. Increasing levels of leptin can down-regulate the adipose mass while leptin resistance may occur in obesity individuals. Recently, it was shown that MT1 signaling could modulate leptin signaling. Rats with melatonin deficiency were observed to have leptin resistance and increased body weight, and these defects were reversed with melatonin administration $[65,66]$. MT1 knock-out mice showed more daily food intake that led to increased body weight compared with the wild type mice, indicating that MT1 is critical in feeding behavior ${ }^{53}$.

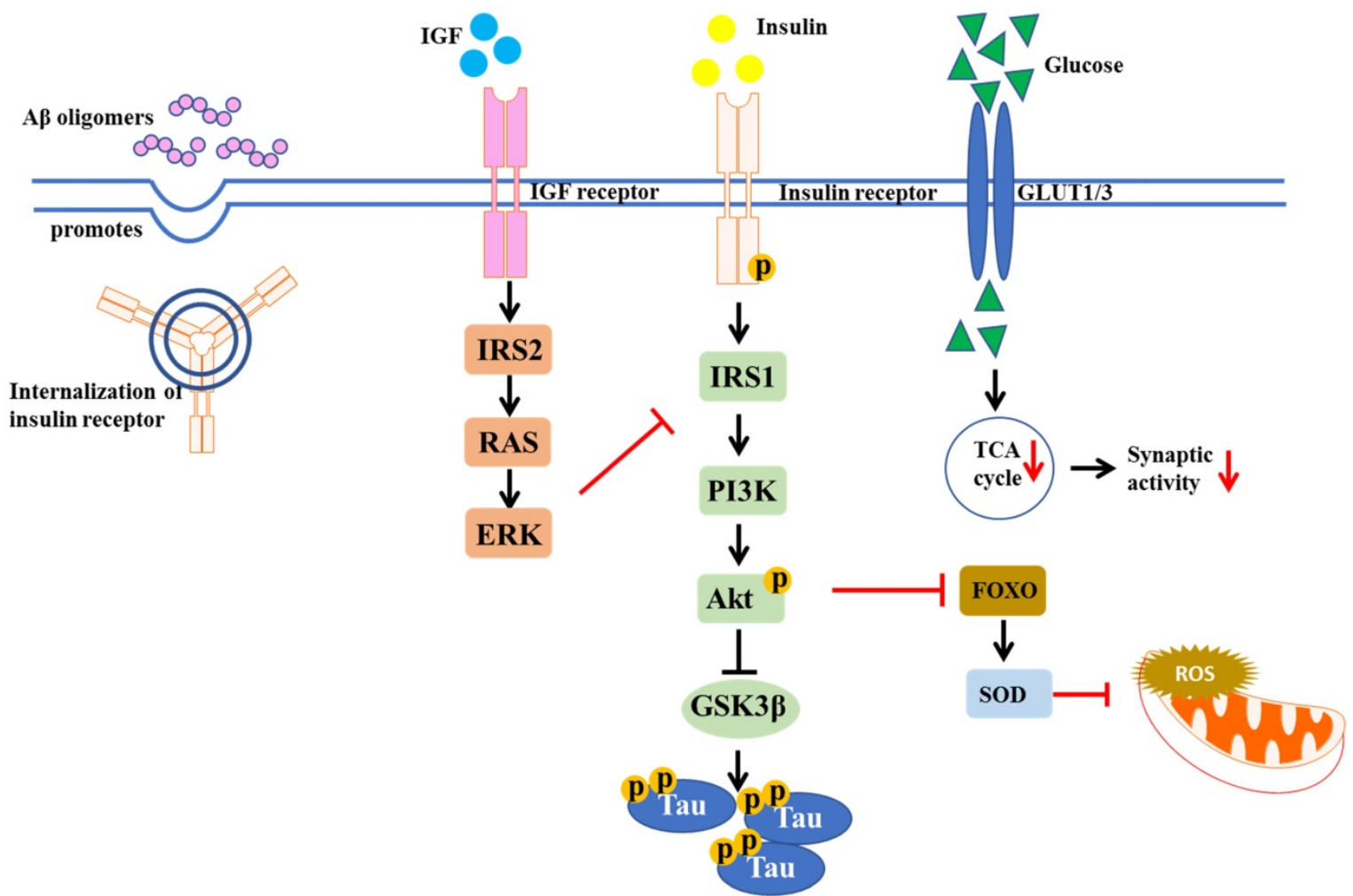

Figure 3. Insulin signaling pathway implicated in T2DM and AD. The diagram shows the defective insulin signaling. IR may result from impairment of insulin receptor function, tyrosine dephosphorylation of insulin receptor and IRS, as well as the disturbance of glucose transportation, which in turn decreases synaptic activity. 
Table 1. Pharmacological studies of melatonin on different T2DM models.

\begin{tabular}{|c|c|c|}
\hline Pharmacological effects & Mechanisms & Ref. \\
\hline \multicolumn{3}{|l|}{ Zücker diabetic fatty (ZDF) rats } \\
\hline Decreased hyperleptinemia; raised hypoadiponectinemia; improved homeostasis & HOMA-IR $\downarrow$; insulin resistance $\downarrow$; serum free fatty acid $\downarrow$ & [45] \\
\hline Attenuated low-grade inflammation and oxidative stress & IL-6, TNF- $\alpha$ and CRP $\downarrow$; inflammation $\downarrow ;$ LPO $\uparrow$; oxidative stress $\downarrow$ & [46] \\
\hline Promoted fat browning & PGC-1a and UCP1 ; mitochondrial function $\uparrow$ & {$[47,48$} \\
\hline Reduced the oxidative status; reduced apoptosis susceptibility & Respiratory control ratio (RCR) $\uparrow$; nitrite levels $\downarrow$; mitochondrial function $\uparrow$ & [35] \\
\hline Prevented impaired functions of hepatic mitochondria in diabetic obese animals & $\begin{array}{l}\text { ALT } \downarrow \text {; glycogen and lipid accumulation } \downarrow \text {; tate } 3 \text { respiration and RCR } \uparrow \text {; } \\
\text { oxidative stress } \downarrow ; \text { UCP } \downarrow \text {; mitochondrial function } \uparrow\end{array}$ & [49] \\
\hline \multicolumn{3}{|l|}{ Combined of HFD and STZ treated rodents } \\
\hline Prevented retinal damage in early T2DM & NOS activity $\downarrow ;$ TNFa $\downarrow$; inflammation $\downarrow$; oxidative stress $\downarrow$; & {$[50]$} \\
\hline Decreased apoptosis; improved cardiac function in T2DM & $\begin{array}{l}\text { SIRT1 signaling } \uparrow \text {; PERK/eIF2a/ATF4 signaling } \downarrow \text {; oxidative stress } \downarrow \text {; ER } \\
\text { stress } \downarrow\end{array}$ & [51] \\
\hline Restored the vascular responses and endothelial dysfunction in diabetes & Fasting blood glucose, total cholesterol and LDL levels $\downarrow$; oxidative stress $\downarrow$ & [52] \\
\hline Increased lipid peroxidation; reduced hypertension and fatigue syndrome & $\begin{array}{l}\text { Lipid profiles } \downarrow \text {; serum adiponectin } \uparrow \text {; GLUT4, PGC-1a, mTFA and NRF } \uparrow \text {; } \\
\text { oxidative stress } \downarrow \text {; insulin resistance } \downarrow\end{array}$ & [53] \\
\hline \multicolumn{3}{|l|}{ HFD-fed rodents } \\
\hline Reduced hyperglycemia & $\begin{array}{l}\text { Total cholesterol and triacylglycerols } \downarrow \text {; blood glucose } \downarrow \text {; insulin resistance } \downarrow \text {; } \\
\text { oxidative stress } \downarrow\end{array}$ & {$[54,55$} \\
\hline Decreased hyperleptinemia; raised hypoadiponectinemia; & HOMA-IR $\downarrow$; insulin resistance $\downarrow$; glucose tolerance $\uparrow$ & {$[42]$} \\
\hline Prevented diabetic cardiomyopathy & Caspase- 3 and Bax $\downarrow$; Bcl-2 $\uparrow$; insulin resistance $\downarrow ;$ ER stress $\downarrow$ & [56] \\
\hline Improved metabolic flexibility & $\begin{array}{l}\text { Total cholesterol, triglycerides and LDL-cholesterol } \downarrow \text {; IL- } 6 \text { and TNFa } \downarrow \text {; } \\
\text { inflammation } \downarrow\end{array}$ & {$[57,58$} \\
\hline Improved brain glucose homeostasis & $\begin{array}{l}\text { GSH } \uparrow \text {; oxidative stress } \downarrow \text {; AChE, iNOS, IL-6, MCP-1 and TNFa } \downarrow \text {; } \\
\text { inflammation } \downarrow\end{array}$ & [45] \\
\hline \multicolumn{3}{|l|}{ T2DM patients } \\
\hline NA & 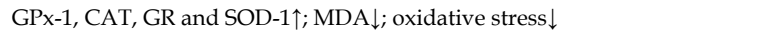 & {$[59,60]$} \\
\hline NA & CRP, IL- 6 and TNF- $\alpha$; inflammation $\downarrow$ & [47] \\
\hline \multicolumn{3}{|l|}{ Pinealectomized rats } \\
\hline Increased energy expenditure; increased mitochondrial respiratory & $\begin{array}{l}\text { PGC- } 1 a, \text { CREB, AKT and CAMKII } \uparrow \text {; mitochondrial biogenesis } \uparrow \\
\text { mitochondrial function } \downarrow \text {; insulin resistance } \downarrow\end{array}$ & {$[61]$} \\
\hline \multicolumn{3}{|l|}{ Rat insulinoma INS-1 cells } \\
\hline Prevented hyperglycemia; rescue $\beta$-cell viability & $\begin{array}{l}\text { glutathione peroxidase, SOD, glutathione reductase and catalase } \uparrow ; \\
\text { mitochondrial function } \uparrow\end{array}$ & [62] \\
\hline \multicolumn{3}{|l|}{ PA induced IR primary muscle cells } \\
\hline Increased energy expenditure; increase mitochondrial respiratory & $\begin{array}{l}\mathrm{UCP} 3, \mathrm{PGC}-1 \alpha, \mathrm{CREB}, \mathrm{AKT} \text { and CAMKII } \uparrow \text { mitochondrial function } \uparrow \text {; insulin } \\
\text { resistance } \downarrow\end{array}$ & [61] \\
\hline
\end{tabular}

Ghrelin plays an essential role in orexigenic behavior. Plasma levels of ghrelin elevate before each daytime meal, decrease after mealtime, and increase progressively during fasting overnight, demonstrating that ghrelin release triggers appetite initiation. Growth hormone secretagogue receptor (GHSR) activated by ghrelin up-regulates the intracellular levels of PIP3 and $\mathrm{Ca}^{2+}$ via triggering PLC and PKC [67]. Increasing $\mathrm{Ca}^{2+}$ influx activates hypothalamic calcium/calmodulin-dependent protein kinase kinase 2 (CaMKK2), followed by AMPK activation [68, 69]. Ghrelin exhibits rhythmic secretion under feeding or fasting conditions. An immunohistochemical study showed that rats which had undergone pinealectomy almost completely abolished ghrelin secretion in the arcuate nucleus (ARC) region [70]. However, ghrelin levels in the plasma of exogenous melatonin treatment or removal of pineal gland were not significantly different from the control group. Thus, it is considered that the interaction between ghrelin and melatonin may be indirect. As mentioned above, serotonin acts as a melatonin precursor and mediates the regulation of appetite, thermogenesis, and higher level of mental functions like memory and learning. It is possible that ghrelin attenuates melatonin release by disrupting serotonin biosynthesis and secretion from pineal gland.

\section{Circadian clock and food intake}

Animals can sense the time of food availability. The ghrelin, glucocorticoids, and glucagon secreted before mealtime are classified as pre-feeding timers. Meanwhile, hormones like insulin and leptin which are secreted after food intake are called post-feeding timers [71]. Avoiding excessive energy intake during rest phase is critical for healthy metabolism [69]. Although melatonin is not strictly recognized as a metabolic hormone, melatonin plays important roles in glucose homeostasis. Melatonin can indirectly modulate feeding behavior on the circadian clock. In mice and rats, melatonin administration decreases adipose mass and body weight [72]. In diet-induced obesity zebrafish, melatonin stimulated the anorexigenic and inhibited the orexigenic signaling [73]. Thus, the lesion of circadian oscillations may disturb the control of energy balance, thus causinging metabolic diseases like obesity and T2DM.

\section{Mitochondria biogenesis and bioactivity}

As previously mentioned, melatonin is an ancient antioxidant. As for the subcellular distribution 
of melatonin, the rank of its concentrations from high to low is mitochondria, cell membranes, nuclei, and cytosol in brain [74]. It is reasonable that antioxidants such as melatonin are efficient in decreasing total oxidative burden, as ROS is highly produced in mitochondria. In addition, it is proposed that melatonin is highly effective as a mitochondria-target antioxidant [75, 76]. The potency of classic antioxidants being limited even in high doses may be due to their difficulty in accessing mitochondria. Therefore, melatonin can be a good candidate to increase the therapeutic effectiveness via anti-oxidative activity.

Mitochondrial dysfunction may accelerate the $\mathrm{AD}$ onset that accompanies aging [77]. A key direct association between aging and mitochondrial function was observed in many models. In rats, aging leads to brain mitochondrial dysfunction, comprising of changes in expression levels of mitochondrial genes and decreased activities of respiratory chain related enzymes [78]. Also, age-related mitochondrial impairment was observed in amyloid-based transgenic mouse models, which act through inhibition of oxidative phosphorylation [79, 80]. Melatonin increased mitochondrial bioactivity, which subsequently attenuated $A \beta$ accumulation and synaptic dysfunction and exhibited neuroprotective effects in AD mice [81, 82]. Also, melatonin administration was effective in $\mathrm{AD}$ models through triggering free radical scavenging cascades [83, 84]. Melatonin treatment on APP/PS1 mice was elucidated to restore the membrane potential, mitochondrial respiratory rates, and ATP levels in cortex, hippocampus, and striatum [85]. These evidences suggest melatonin or activating melatonin receptor signaling can be a potential strategy in delaying AD progression.

The circadian clock is important in metabolism according to both human epidemiological and interventional studies. Disruptions of circadian genes lead to striking metabolic disturbances [86]. It is only recently understood that circadian disruption might contribute to diabetes and $\beta$-cell dysfunction [87]. In T2DM rats, melatonin supplementation combined with exercise showed increased expression of mitochondrial biogenesis and function-related genes, including mtTFA, PGC1- $\alpha$, NRF-1, and NRF-2. Moreover, melatonin intake combined with exercise is effective in scavenging toxic free radicals, suggesting melatonin administration showed anti-diabetic effects via anti-oxidative pathways [53]. Recently, melatonin was shown to increase thermogenesis by enhancing mitochondrial biogenesis and respiration in intramuscular adipocytes of HFD-fed mice [88]. Notably, melatonin treatment prevented mitochondrial fission via SIRT1/PGC-1a activation in hyperglycemia-treated cells and streptozocin (STZ)-induced diabetic mice [89]. Melatonin is expected to reach maximal plasma levels after 30-60 min in oral administration and 30-45 $\mathrm{min}$ in intravenous (IV) administration [90]. The elimination half-life (t1/2) for a dose of 0.5-6 mg melatonin in oral administration is approximately $46-65 \mathrm{~min}$, while the $\mathrm{t} 1 / 2$ is about $28-61 \mathrm{~min}$ for IV administration of 100 mg melatonin [90, 91]. Also, melatonin metabolism acts faster in children than adults. To improve the bioavailability of melatonin, the strategies including subcutaneous injection, oral transmucosal, intranasal, and transdermal can be considered [92].

\section{Melatonin can possibly halt or even prevent the pathogenesis of T2DM-induced AD-like features}

In the previous sections, we have summarized that the mechanisms of metabolic diseases in decreasing cognitive functions may be related to oxidative stress, mitochondrial dysfunction, IR, and inflammation. In this section, we discuss the effects of melatonin in preventing T2DM (or related diseases)-induced AD pathology. As shown in Table 2 , different mechanisms of melatonin in treating $\mathrm{AD}$ are summarized.

Melatonin can be secreted into the blood, CSF, brain and peripheral tissues. Melatonin (5-methoxy$\mathrm{N}$-acetyltryptamine) is a pleiotropic hormone derived from vertebrate pineal glands to regulate the circadian and seasonal rhythms, sleep, retinal functions and the immune system [106, 107]. The first step of melatonin biosynthesis is the hydroxylation of tryptophan to generate 5-hydroxytryptophan, and then 5-hydroxytryptophan is decarboxylated to produce serotonin. Next, the arylakylamine N-acetyltransferase acetylates serotonin to $\mathrm{N}$-acetylserotonin. Finally, $\mathrm{N}$-acetylserotonin is methylated by O-methyltransferase to generate melatonin [108]. The synthesis of melatonin is regulated in a circadian manner. After biosythesis, melatonin is right to be transferred into the cerebrospinal fluid (CSF) and bloodstream. Melatonin exists like a transient state in the body that is rapidly metabolized in the body and its half-life is only around 20-30 min [109]. Melatonin has been observed to be a free radical scavenger, immune modulator, and neuroprotectant [110]. Melatonin treatment was found to improve cognitive function and reverse sleeplessness in neurodegenerative diseases, through Nrf2 activation and inhibition of proinflammatory cytokines [111]. In AD patients, $A \beta$ accumulation and proinflammatory cytokines impair the BBB permeability. 
Table 2. Pharmacological studies of melatonin on different AD models.

\begin{tabular}{|c|c|c|c|}
\hline Pharmacological effects & Behavioral or cognitive changes & Mechanisms & Ref. \\
\hline \multicolumn{4}{|l|}{ Amyloid-beta induced AD rats } \\
\hline $\begin{array}{l}\text { Improved spatial learning and memory, } \\
\text { synaptic plasticity; reduced astrogliosis and } \\
\text { synaptotoxicity }\end{array}$ & $\begin{array}{l}\text { Less time to reach the platform in Morris water maze (MWM) test; more } \\
\text { efficient in swimming path }\end{array}$ & GFAP $\downarrow ;$ Musashi1/Notch1/Hes1 $\uparrow$ & $\begin{array}{l}{[93,} \\
94]\end{array}$ \\
\hline $\begin{array}{l}\text { Inhibited neurotoxicity and astrocyte } \\
\text { activation }\end{array}$ & NA & GFAP $\downarrow ; \mathrm{MAP} \uparrow ;$ Reelin/Dab1 $\uparrow$ & [78] \\
\hline Improved spatial learning and memory & $\begin{array}{l}\text { Shorter latency in MWM test; increase of period in the III quadrant, raise } \\
\text { of numbers of line crossings in central square arena in open field test; } \\
\text { increase in the latency and decreased errors in step-through test and step- } \\
\text { down test }\end{array}$ & $\begin{array}{l}\text { GSK- } 3 \beta \text {, caspase- } 3, \mathrm{~A} \beta 1-42, \mathrm{BACE} 1 \text { and } \\
\text { p-tau } \downarrow ; \mathrm{PP} 2 \mathrm{~A} \text { and } \mathrm{Bcl}-2 \uparrow ; \text { mitochondrial } \\
\text { function } \uparrow\end{array}$ & [95] \\
\hline $\begin{array}{l}\text { Improved memory, hindered anxiety, and } \\
\text { attenuated hippocampal cell damage }\end{array}$ & $\begin{array}{l}\text { Increased number of arm entries in Y-maze test; increased number of } \\
\text { open arm entries and time spent in open arms in EPM test }\end{array}$ & SIRT1 $\uparrow ;$ COX2 and TFAM $\uparrow$ & {$[80]$} \\
\hline \multicolumn{4}{|l|}{ Scopolamine induced amnesia mice } \\
\hline Improved spatial learning and memory & $\begin{array}{l}\text { Shorter escape latency in MWM test; longer latency time in passive } \\
\text { avoidance test (PAT) }\end{array}$ & ChAT, CHT and VAChT $\uparrow$ & [96] \\
\hline Recovered cognitive impairment & Shorter escape latency in MWM test; longer latency time in PAT & $\mathrm{MBP}, \mathrm{BDNF}$, and TrkB $\uparrow$ & [97] \\
\hline $\begin{array}{l}\text { Attenuated synaptic dysfunction, memory } \\
\text { impairment neuroinflammation }\end{array}$ & $\begin{array}{l}\text { Shorter escape latency in MWM test; increased number of arm entries in } \\
\text { Y-maze test }\end{array}$ & $\begin{array}{l}\text { CREB and BDNF } \uparrow \text {; Akt and ERK } \uparrow \text {; GFAP, } \\
\text { TNFa and IL6 } \downarrow ; \text { JNK, Nrf2 and HO- } 1 \downarrow\end{array}$ & [98] \\
\hline \multicolumn{4}{|l|}{ Tg2576 mice overexpressed APP } \\
\hline $\begin{array}{l}\text { Ameliorated amygdala-dependent } \\
\text { emotional memory }\end{array}$ & No changes in behavioral tests & PSD95 $\downarrow ;$ Arc, pCREB and c-Fos $\uparrow$ & [99] \\
\hline Activated lymphatic system & NA & $\mathrm{A} \beta \downarrow$ & $\begin{array}{l}{[100,} \\
101]\end{array}$ \\
\hline \multicolumn{4}{|l|}{ AD transgenic mice } \\
\hline $\begin{array}{l}\text { Induced cognitive enhancement and brain } \\
\text { resilience }\end{array}$ & Novel object recognition (NOR) test & $\begin{array}{l}\text { NF-kB, TNFa, IL-1 } 1 \beta \downarrow \text {; amyloid and p-tau } \downarrow \text {; } \\
\text { Gas6 and SIRT1 } \uparrow\end{array}$ & [85] \\
\hline $\begin{array}{l}\text { Improved episodic memory; reduced } \\
\text { neuroinflammation; inhibited reactive } \\
\text { microgliosis }\end{array}$ & Less time spent exploring the new object & amyloid aggregates $\downarrow$ & [102] \\
\hline \multicolumn{4}{|l|}{ STZ-induced AD like rats } \\
\hline $\begin{array}{l}\text { Prevented memory impairment; } \\
\text { downregulated AD-like } \\
\text { hyperphosphorylation }\end{array}$ & Shorter escape latency in MWM test & $\begin{array}{l}\text { MDA } \downarrow ; \text { SOD and GSH-Px } \uparrow \text {; antioxidation } \\
\text { function } \uparrow\end{array}$ & [103] \\
\hline $\begin{array}{l}\text { Ameliorated memory; prevented brain } \\
\text { insulin resistance }\end{array}$ & Shorter escape latency in MWM test & p-tau, BACE1 and PS1 $\downarrow ;$ AKT and GSK-3 $\beta \uparrow$ & [104] \\
\hline \multicolumn{4}{|l|}{ Aged mice } \\
\hline $\begin{array}{l}\text { Improved hippocampal neuronal } \\
\text { homeostasis }\end{array}$ & NA & $\begin{array}{l}\text { SIRT1, FOXO1, MT1 and MT2 } \uparrow ; \text { p } 53 \text {, ac-p } 53 \text {, } \\
\text { MDM2, and DKK1 }\end{array}$ & {$[105]$} \\
\hline
\end{tabular}

The BBB breakdown, accompanying increased levels of ROS, metalloproteinase (MMP)-2, and IFNY, could enhance the circulating neurotoxins enter the brain due to selectivity loss, and finally exacerbate AD progression [112]. The disruption of BBB has also been observed in T2DM individuals by changing its permeability and integrity $[106,107]$. In addition, the permeability of BBB increased via alteration of the tight junction protein expression in STZ-induced diabetic rats [113]. In obese individuals, the macrophage infiltrated in adipocytes undergo M1 proinflammatory state, leading to excessive secretion of proinflammatory cytokines and chemokines, which can cross the BBB and affect brain functions [114]. Melatonin has protective effects in brain microvascular endothelial cell via MMP-9 and nicotinamide adenine dinucleotide phosphate (NADPH) oxidase-2 expression [115, 116].

In HFD-induced cognitive impairment mice, melatonin was shown to prevent the oxidative stress in hippocampus through decreasing the level of GSSG and increasing GSH/GSSG ratio [117]. In STZ-induced rats which displayed AD features, melatonin was effective in decreasing both $A \beta$ formation and tau proteins hyperphosphorylation in hippocampus, as well as reducing the phosphorylation of IRS1 and restoring the phosphorylation of glycogen synthase kinase $3 \beta$ (GSK3 $\beta$ ) [104]. These observations indicate that melatonin may be protective in individuals suffering from diabetes and slow down the progression to $\mathrm{AD}$, via restoring insulin signaling. Moreover, the role of melatonin in GSK3 $\beta$ regulation elucidated that GSK3 $\beta$ would interact with presenilin-1 to prevent neurodegeneration in AD $[118,119]$. Chronic melatonin exposure could attenuate the tau protein hyperphosphorylation via activating PI3K/Akt/ GSK $3 \beta$ in $A \beta_{42}$ treated mice. It was also reported that melatonin could prevent T2DM-induced cognitive deficits in rats through anti-neuroinflammatory activity. In the combination of HFD and STZ-induced cognitive dysfunction rats, melatonin treatment was shown to significantly reduce the expression levels of the neuroinflammatory mediated factor including IL-6, TNF-a, iNOS and COX-2, along with inhibiting the expression of NF-KB and IKK phosphorylation, as well as mitigating increasing mitochondrial function [120]. Besides, the neuroinflammation found in 
HFD-induced T2DM rat could be reversed with melatonin treatment, accompanying with repression of iNOS, IDO1, and AChE, indicating that the antioxidant and anti-inflammatory effects of melatonin can be applied in fighting against neuroinflammation associated with T2DM [58]. It is belived that melatonin will be a potential strategy in both T2DM and AD therapy through reversing IR (Figure 4).

\section{Safety of melatonin}

Melatonin can act as a broad spectrum antioxidant partially due to its lipophilic and hydrophilic properties, which can cross the barriers easily within subcellular organelles. Although limited data concluded the safety of exogenous melatonin, it can be suggested as a safe drug. Melatonin showed no significant adverse effects on adolescents, children, or preterm infants except high doses or long-time administration [121, 122]. In children with epilepsy, a dosage of $9 \mathrm{mg}$ per day for 4 weeks may have adverse effects including headache, diarrhea, hypothermia, dizziness, rash, and gastrointestinal symptoms [123]. In seasonally breeding mammals, melatonin was shown to decrease estrogen secretion in long-breeders but increase estrogen levels in short-breeders [124, 125]. However, the side effects of melatonin on reproduction of human beings remain unknown. Since the dosage of melatonin in pregnancy subjects is not studied, it is not recommended for pregnant women to use melatonin [126]. It is hypothesized that melatonin may affect the ovaries but the exact mechanisms need to be determined [127].

\section{Conclusion and perspectives}

Melatonin acts like a master clock in the suprachiasmatic nuclei (SCN) and is associated with multi-oscillatory network in mammal organisms [128]. Based on existing studies, deviant circadian rhythms and poor sleep quality may increase the risk of metabolic and cognitive diseases. Some reports have suggested that endogenous melatonin showed protective effects on endocrine and neurological systems. Melatonin is also important in regulating the

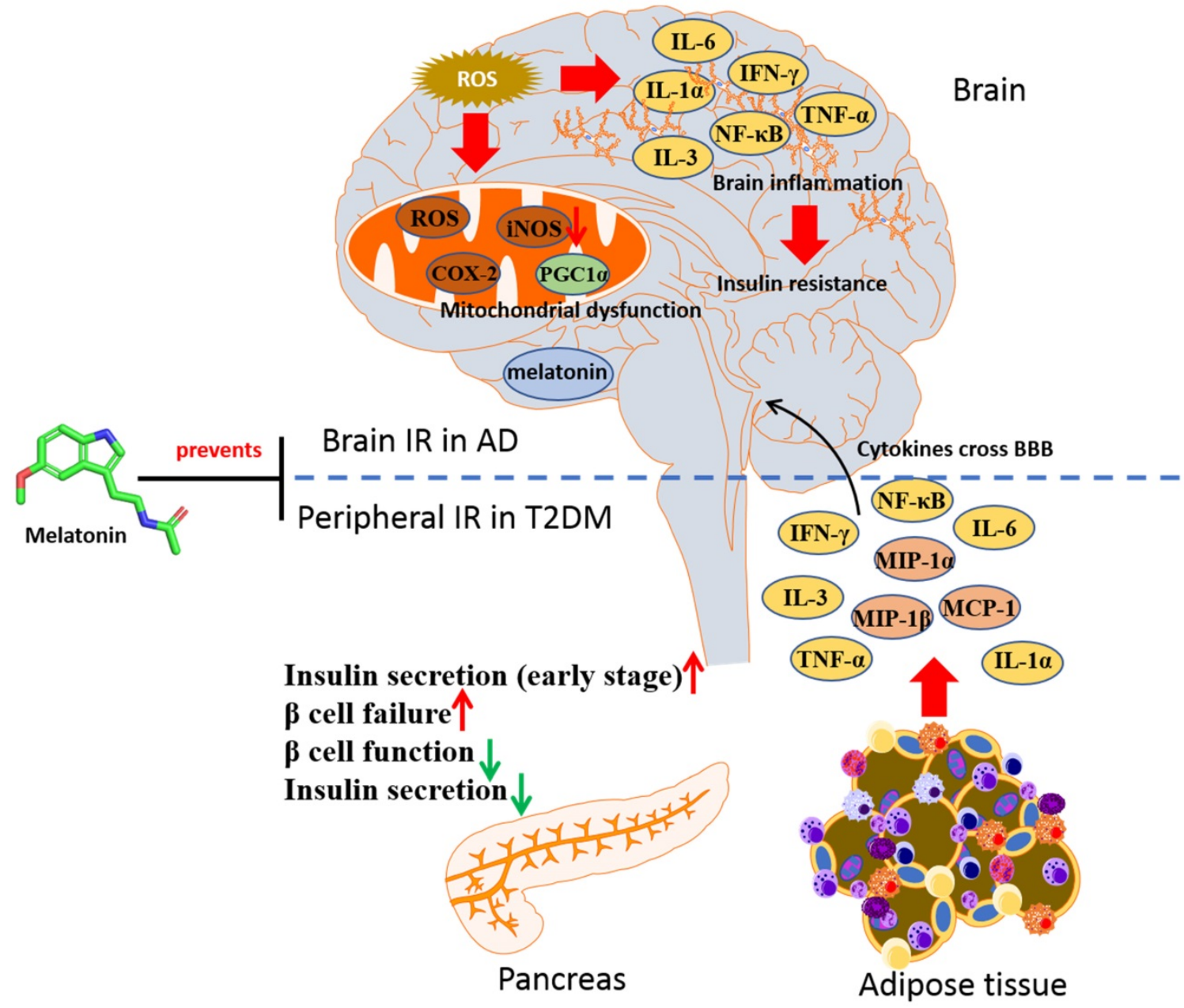

Figure 4. Melatonin in prevention against insulin resistance of AD and T2DM. In T2DM, a parallel inflammatory mechanism leads to brain insulin resistance and cognitive dysfunction in AD. Melatonin can be an agent in halt the progression of AD in T2DM by targeting insulin signaling. 
secretion of metabolic hormones like leptin and ghrelin, which are key mediators in energy homeostasis. In experimental models of $\mathrm{AD}$, the neurodegenerative symptoms were prevented by melatonin via the removal of toxic proteins by the brain glymphatic system. These studies indicated that melatonin is beneficial in T2DM and AD, although it remains inconclusive whether melatonin treatment in patients might raise any adverse effects.

Numerous studies have demonstrated that T2DM could accelerate and exacerbate AD. There are overlapping mechanisms of T2DM and AD including oxidative stress, mitochondrial dysfunction, IR, and inflammation. IR is a characteristic of T2DM, and a potential indicator of AD. Melatonin seems to meet the criteria of exhibiting highly significant protective actions against these conditions, especially in T2DM induced $\mathrm{AD}$, by targeting the metabolic pathways regulated by brain insulin. Currently, the adverse effects of melatonin is yet to be elucidated in detail but most of the effects of melatonin have been proven to be safe in human and animal models at various dose ranges. Considering the high efficacy of melatonin in increasing mitochondrial bioactivity and insulin sensitivity, it provides an insight to investigate the clinical efficacy and safety of melatonin in halting the progression of $\mathrm{AD}$ in $\mathrm{T} 2 \mathrm{DM}$ individuals.

\section{Acknowledgements}

We gratefully acknowledge financial support from the National Key Research and Development Program of China (2020YFA0908000 and 2020YFE0205100); the National Natural Science Foundation of China $(81903588,81803456,81702580$, 82074098, 81841001, 81903866, 81803389, 82104183); the CACMS Innovation Fund (CI2021A05101); the Fundamental Research Funds for the Central public welfare research institutes (ZZ13-ZD-07, ZZ14-YQ-050, ZZ14-YQ-051, ZZ14-YQ-056, ZZ14-ND-010 and ZZ15-ND-10); the Macau Young Scholars Program (AM2020027), the Innovation Team and Talents Cultivation Program of National Administration of Traditional Chinese Medicine (ZYYCXTD-C-202002).

\section{Competing Interests}

The authors have declared that no competing interest exists.

\section{References}

1. Arnold SE, Arvanitakis Z, Macauley-Rambach SL, Koenig AM, Wang HY, Ahima RS, et al. Brain insulin resistance in type 2 diabetes and Alzheimer disease: concepts and conundrums. Nat Rev Neurol. 2018; 14: 168-81.

2. Sims-Robinson C, Kim B, Rosko A, Feldman EL. How does diabetes accelerate Alzheimer disease pathology? Nat Rev Neurol. 2010; 6: 551-9.
3. Bouatia-Naji N, Bonnefond A, Cavalcanti-Proenca C, Sparso T, Holmkvist J, Marchand M, et al. A variant near MTNR1B is associated with increased fasting plasma glucose levels and type 2 diabetes risk. Nat Genet. 2009; 41: 89-94.

4. Fernandez Vazquez G, Reiter RJ, Agil A. Melatonin increases brown adipose tissue mass and function in Zucker diabetic fatty rats: implications for obesity control. J Pineal Res. 2018; 64: e12472.

5. Shukla M, Govitrapong P, Boontem P, Reiter RJ, Satayavivad J. Mechanisms of Melatonin in Alleviating Alzheimer's Disease. Curr Neuropharmacol. 2017; 15: 1010-31.

6. Spinedi E, Cardinali DP. Neuroendocrine-Metabolic Dysfunction and Sleep Disturbances in Neurodegenerative Disorders: Focus on Alzheimer's Disease and Melatonin. Neuroendocrinology. 2019; 108: 354-64.

7. Holscher C. Insulin Signaling Impairment in the Brain as a Risk Factor in Alzheimer's Disease. Front Aging Neurosci. 2019; 11: 88.

8. Frolich L, Blum-Degen D, Bernstein HG, Engelsberger S, Humrich J, Laufer $\mathrm{S}$, et al. Brain insulin and insulin receptors in aging and sporadic Alzheimer's disease. J Neural Transm (Vienna). 1998; 105: 423-38.

9. Heras-Sandoval D, Perez-Rojas JM, Hernandez-Damian J, Pedraza-Chaverri J. The role of $\mathrm{PI} 3 \mathrm{~K} / \mathrm{AKT} / \mathrm{mTOR}$ pathway in the modulation of autophagy and the clearance of protein aggregates in neurodegeneration. Cell Signal. 2014; 26: 2694-701.

10. Holscher C. Insulin, incretins and other growth factors as potential novel treatments for Alzheimer's and Parkinson's diseases. Biochem Soc Trans. 2014; 42: 593-9.

11. Song $Y$, Ding W, Bei $Y$, Xiao $Y$, Tong HD, Wang LB, et al. Insulin is a potential antioxidant for diabetes-associated cognitive decline via regulating Nrf2 dependent antioxidant enzymes. Biomed Pharmacother. 2018; 104: 474-84.

12. Ferrario CR, Reagan LP. Insulin-mediated synaptic plasticity in the CNS: Anatomical, functional and temporal contexts. Neuropharmacology. 2018; 136: 182-91.

13. Crane PK, Walker R, Hubbard RA, Li G, Nathan DM, Zheng H, et al. Glucose levels and risk of dementia. N Engl J Med. 2013; 369: 540-8.

14. Beydoun MA, Beydoun HA, Wang Y. Obesity and central obesity as risk factors for incident dementia and its subtypes: a systematic review and meta-analysis. Obes Rev. 2008; 9: 204-18.

15. Cameron B, Landreth GE. Inflammation, microglia, and Alzheimer's disease. Neurobiol Dis. 2010; 37: 503-9.

16. van de Sande-Lee $S$, Pereira FR, Cintra DE, Fernandes PT, Cardoso AR, Garlipp CR, et al. Partial reversibility of hypothalamic dysfunction and changes in brain activity after body mass reduction in obese subjects. Diabetes. 2011; 60: 1699-704.

17. Bomfim TR, Forny-Germano L, Sathler LB, Brito-Moreira J, Houzel JC, Decker $\mathrm{H}$, et al. An anti-diabetes agent protects the mouse brain from defective insulin signaling caused by Alzheimer's disease- associated Abeta oligomers. J Clin Invest. 2012; 122: 1339-53.

18. Calay ES, Hotamisligil GS. Turning off the inflammatory, but not the metabolic, flames. Nat Med. 2013; 19: 265-7.

19. Sankar SB, Infante-Garcia C, Weinstock LD, Ramos-Rodriguez JJ, Hierro-Bujalance C, Fernandez-Ponce C, et al. Amyloid beta and diabetic pathology cooperatively stimulate cytokine expression in an Alzheimer's mouse model. J Neuroinflammation. 2020; 17: 38.

20. Go M, Kou J, Lim JE, Yang J, Fukuchi KI. Microglial response to LPS increases in wild-type mice during aging but diminishes in an Alzheimer's mouse model: Implication of TLR4 signaling in disease progression. Biochem Biophys Res Commun. 2016; 479: 331-7.

21. Brabazon F, Bermudez S, Shaughness M, Khayrullina G, Byrnes KR. The effects of insulin on the inflammatory activity of BV2 microglia. PLoS One. 2018; 13: e0201878.

22. Fan Z, Brooks DJ, Okello A, Edison P. An early and late peak in microglial activation in Alzheimer's disease trajectory. Brain. 2017; 140: 792-803.

23. Kandimalla R, Thirumala V, Reddy PH. Is Alzheimer's disease a Type 3 Diabetes? A critical appraisal. Biochim Biophys Acta Mol Basis Dis. 2017; 1863: 1078-89.

24. Cai C, Dai X, Zhu Y, Lian M, Xiao F, Dong F, et al. A specific RAGE-binding peptide biopanning from phage display random peptide library that ameliorates symptoms in amyloid beta peptide-mediated neuronal disorder. Appl Microbiol Biotechnol. 2016; 100: 825-35.

25. Zhang T, Chen D, Lee TH. Phosphorylation Signaling in APP Processing in Alzheimer's Disease. Int J Mol Sci. 2019; 21.

26. Anderson EJ, Lustig ME, Boyle KE, Woodlief TL, Kane DA, Lin CT, et al. Mitochondrial $\mathrm{H} 2 \mathrm{O} 2$ emission and cellular redox state link excess fat intake to insulin resistance in both rodents and humans. J Clin Invest. 2009; 119: 573-81.

27. Pitt J, Wilcox KC, Tortelli V, Diniz LP, Oliveira MS, Dobbins C, et al. Neuroprotective astrocyte-derived insulin/insulin-like growth factor 1 
stimulates endocytic processing and extracellular release of neuron-bound A $\beta$ oligomers. Mol Biol Cell. 2017; 28: 2623-36.

28. Kurochkin IV, Guarnera E, Berezovsky IN. Insulin-Degrading Enzyme in the Fight against Alzheimer's Disease. Trends Pharmacol Sci. 2018; 39: $49-58$.

29. Liu J, Chang L, Song Y, Li H, Wu Y. The Role of NMDA Receptors in Alzheimer's Disease. Front Neurosci. 2019; 13: 43.

30. Picone P, Giacomazza D, Vetri V, Carrotta R, Militello V, San Biagio PL, et al. Insulin-activated Akt rescues Abeta oxidative stress-induced cell death by orchestrating molecular trafficking. Aging Cell. 2011; 10: $832-43$

31. De Meyts P. The Insulin Receptor and Its Signal Transduction Network. In: Feingold KR, Anawalt B, Boyce A, Chrousos G, Dungan K, Grossman A, et al., editors. Endotext. South Dartmouth (MA); 2000.

32. Rodriguez-Rodriguez $\mathrm{P}$, Sandebring-Matton A, Merino-Serrais $\mathrm{P}$, Parrado-Fernandez C, Rabano A, Winblad B, et al. Tau hyperphosphorylation induces oligomeric insulin accumulation and insulin resistance in neurons. Brain. 2017; 140: 3269-85.

33. Laws SM, Gaskin S, Woodfield A, Srikanth V, Bruce D, Fraser PE, et al. Insulin resistance is associated with reductions in specific cognitive domains and increases in CSF tau in cognitively normal adults. Sci Rep. 2017; 7: 9766.

34. Goncalves RA, Wijesekara N, Fraser PE, De Felice FG. The Link Between Tau and Insulin Signaling: Implications for Alzheimer's Disease and Other Tauopathies. Front Cell Neurosci. 2019; 13: 17.

35. Gratuze M, Julien J, Petry FR, Morin F, Planel E. Insulin deprivation induces PP2A inhibition and tau hyperphosphorylation in hTau mice, a model of Alzheimer's disease-like tau pathology. Sci Rep. 2017; 7: 46359.

36. Zhang Y, Huang NQ, Yan F, Jin H, Zhou SY, Shi JS, et al. Diabetes mellitus and Alzheimer's disease: GSK-3beta as a potential link. Behav Brain Res. 2018; 339: 57-65.

37. Jockers R, Delagrange P, Dubocovich ML, Markus RP, Renault N, Tosini G, et al. Update on melatonin receptors: IUPHAR Review 20. Br J Pharmacol. 2016; 173: 2702-25.

38. von Gall C, Stehle JH, Weaver DR. Mammalian melatonin receptors: molecular biology and signal transduction. Cell Tissue Res. 2002; 309: 151-62.

39. Bonnefond A, Clement N, Fawcett K, Yengo L, Vaillant E, Guillaume JL, et al. Rare MTNR1B variants impairing melatonin receptor 1B function contribute to type 2 diabetes. Nat Genet. 2012; 44: 297-301.

40. Karamitri A, Plouffe B, Bonnefond A, Chen M, Gallion J, Guillaume JL, et al. Type 2 diabetes-associated variants of the MT2 melatonin receptor affect distinct modes of signaling. Sci Signal. 2018; 11.

41. Owino S, Sanchez-Bretano A, Tchio C, Cecon E, Karamitri A, Dam J, et al. Nocturnal activation of melatonin receptor type 1 signaling modulates diurnal insulin sensitivity via regulation of PI3K activity. J Pineal Res. 2018; 64.

42. Tuomi T, Nagorny CLF, Singh P, Bennet H, Yu Q, Alenkvist I, et al. Increased Melatonin Signaling Is a Risk Factor for Type 2 Diabetes. Cell Metab. 2016; 23: 1067-77.

43. Lin YC, Hsieh IC, Chen PC. Utilizing the metabolic syndrome component count in workers' health surveillance: An example of day-time vs. day-night rotating shift workers. Int J Occup Med Environ Health. 2015; 28: 675-88.

44. Molzof HE, Wirth MD, Burch JB, Shivappa N, Hebert JR, Johnson RL, et al. The impact of meal timing on cardiometabolic syndrome indicators in shift workers. Chronobiol Int. 2017; 34: 337-48.

45. Agil A, Rosado I, Ruiz R, Figueroa A, Zen N, Fernández-Vázquez G. Melatonin improves glucose homeostasis in young Zucker diabetic fatty rats. J Pineal Res. 2012; 52: 203-10.

46. Agil A, Reiter RJ, Jiménez-Aranda A, Ibán-Arias R, Navarro-Alarcón M, Marchal JA, et al. Melatonin ameliorates low-grade inflammation and oxidative stress in young Zucker diabetic fatty rats. J Pineal Res. 2013; 54: 381-8.

47. Jiménez-Aranda A, Fernández-Vázquez G, Campos D, Tassi M, Velasco-Perez L, Tan DX, et al. Melatonin induces browning of inguinal white adipose tissue in Zucker diabetic fatty rats. J Pineal Res. 2013; 55: 416-23.

48. Jimenéz-Aranda A, Fernández-Vázquez G, Mohammad ASM, Reiter RJ, Agil A. Melatonin improves mitochondrial function in inguinal white adipose tissue of Zücker diabetic fatty rats. J Pineal Res. 2014; 57: 103-9.

49. Agil A, El-Hammadi M, Jiménez-Aranda A, Tassi M, Abdo W, Fernández-Vázquez G, et al. Melatonin reduces hepatic mitochondrial dysfunction in diabetic obese rats. J Pineal Res. 2015; 59: 70-9.

50. Salido EM, Bordone M, De Laurentiis A, Chianelli M, Keller Sarmiento MI, Dorfman D, et al. Therapeutic efficacy of melatonin in reducing retinal damage in an experimental model of early type 2 diabetes in rats. J Pineal Res. 2013; 54: 179-89.
51. Yu L, Liang H, Dong X, Zhao G, Jin Z, Zhai M, et al. Reduced silent information regulator 1 signaling exacerbates myocardial ischemia-reperfusion injury in type 2 diabetic rats and the protective effect of melatonin. J Pineal Res. 2015; 59: 376-90.

52. Salmanoglu DS, Gurpinar T, Vural K, Ekerbicer N, Darıverenli E, Var A. Melatonin and L-carnitin improves endothelial disfunction and oxidative stress in Type 2 diabetic rats. Redox biology. 2016; 8: 199-204.

53. Rahman MM, Kwon HS, Kim MJ, Go HK, Oak MH, Kim DH. Melatonin supplementation plus exercise behavior ameliorate insulin resistance, hypertension and fatigue in a rat model of type 2 diabetes mellitus. Biomed Pharmacother. 2017; 92: 606-14.

54. Doddigarla Z, Ahmad J, Parwez I. Effect of chromium picolinate and melatonin either in single or in a combination in high carbohydrate diet-fed male Wistar rats. BioFactors (Oxford, England). 2016; 42: 106-14.

55. Thomas AP, Hoang J, Vongbunyong K, Nguyen A, Rakshit K, Matveyenko AV. Administration of Melatonin and Metformin Prevents Deleterious Effects of Circadian Disruption and Obesity in Male Rats. Endocrinology. 2016; 157: 4720-31.

56. Xiong FY, Tang ST, Su H, Tang HQ, Jiang P, Zhou Q, et al. Melatonin ameliorates myocardial apoptosis by suppressing endoplasmic reticulum stress in rats with longterm diabetic cardiomyopathy. Mol Med Rep. 2018; 17: 374-81.

57. Farias T, Paixao RID, Cruz MM, de Sa R, Simão JJ, Antraco VI, et al. Melatonin Supplementation Attenuates the Pro-Inflammatory Adipokines Expression in Visceral Fat from Obese Mice Induced by A High-Fat Diet. Cells. 2019; 8.

58. Maher AM, Saleh SR, Elguindy NM, Hashem HM, Yacout GA. Exogenous melatonin restrains neuroinflammation in high fat diet induced diabetic rats through attenuating indoleamine 2,3-dioxygenase 1 expression. Life Sci. 2020; 247: 117427.

59. Rybka J, Kędziora-Kornatowska K, Kupczyk D, Muszalik M, Kornatowski M, Kędziora J. Antioxidant effect of immediate- versus sustained-release melatonin in type 2 diabetes mellitus and healthy controls. Drug delivery. 2016; 23: 814-7.

60. Cutando A, Montero J, Gómez-de Diego R, Ferrera MJ, Lopez-Valverde A. Effect of topical application of melatonin on serum levels of C-reactive protein (CRP), interleukin-6 (IL-6) and tumor necrosis factor-alpha (TNF-a) in patients with type 1 or type 2 diabetes and periodontal disease. Journal of clinical and experimental dentistry. 2015; 7: e628-33.

61. Teodoro BG, Baraldi FG, Sampaio IH, Bomfim LH, Queiroz AL, Passos MA, et al. Melatonin prevents mitochondrial dysfunction and insulin resistance in rat skeletal muscle. J Pineal Res. 2014; 57: 155-67.

62. Park JH, Shim HM, Na AY, Bae KC, Bae JH, Im SS, et al. Melatonin prevents pancreatic $\beta$-cell loss due to glucotoxicity: the relationship between oxidative stress and endoplasmic reticulum stress. J Pineal Res. 2014; 56: 143-53.

63. Banks AS, Davis SM, Bates SH, Myers MG, Jr. Activation of downstream signals by the long form of the leptin receptor. J Biol Chem. 2000; 275: 14563-72

64. Vaisse C, Halaas JL, Horvath CM, Darnell JE, Jr., Stoffel M, Friedman JM. Leptin activation of Stat3 in the hypothalamus of wild-type and ob/ob mice but not db/db mice. Nat Genet. 1996; 14: 95-7.

65. Buonfiglio D, Parthimos R, Dantas R, Cerqueira Silva R, Gomes G, Andrade-Silva J, et al. Melatonin Absence Leads to Long-Term Leptin Resistance and Overweight in Rats. Front Endocrinol (Lausanne). 2018; 9: 122.

66. Buonfiglio D, Tchio C, Furigo I, Donato J, Jr., Baba K, Cipolla-Neto J, et al. Removing melatonin receptor type 1 signaling leads to selective leptin resistance in the arcuate nucleus. J Pineal Res. 2019; 67: e12580.

67. van der Lely AJ, Tschop M, Heiman ML, Ghigo E. Biological, physiological, pathophysiological, and pharmacological aspects of ghrelin. Endocr Rev. 2004; 25: 426-57.

68. Anderson KA, Ribar TJ, Lin F, Noeldner PK, Green MF, Muehlbauer MJ, et al. Hypothalamic CaMKK2 contributes to the regulation of energy balance. Cell Metab. 2008; 7: 377-88

69. Kirsz K, Zieba DA. Ghrelin-mediated appetite regulation in the central nervous system. Peptides. 2011; 32: 2256-64.

70. Canpolat S, Aydin M, Yasar A, Colakoglu N, Yilmaz B, Kelestimur H. Effects of pinealectomy and exogenous melatonin on immunohistochemical ghrelin staining of arcuate nucleus and serum ghrelin leves in the rat. Neurosci Lett. 2006; 410: 132-6.

71. Challet E. Keeping circadian time with hormones. Diabetes Obes Metab. 2015; 17 Suppl 1: 76-83.

72. Cipolla-Neto J, Amaral FG, Afeche SC, Tan DX, Reiter RJ. Melatonin, energy metabolism, and obesity: a review. J Pineal Res. 2014; 56: 371-81.

73. Montalbano G, Mania M, Abbate F, Navarra M, Guerrera MC, Laura R, et al. Melatonin treatment suppresses appetite genes and improves adipose tissue plasticity in diet-induced obese zebrafish. Endocrine. 2018; 62: 381-93. 
74. Venegas C, Garcia JA, Escames G, Ortiz F, Lopez A, Doerrier C, et al. Extrapineal melatonin: analysis of its subcellular distribution and daily fluctuations. J Pineal Res. 2012; 52: 217-27.

75. Reiter RJ, Mayo JC, Tan DX, Sainz RM, Alatorre-Jimenez M, Qin L. Melatonin as an antioxidant: under promises but over delivers. J Pineal Res. 2016; 61: 253-78.

76. Wang L, Feng C, Zheng X, Guo Y, Zhou F, Shan D, et al. Plant mitochondria synthesize melatonin and enhance the tolerance of plants to drought stress. J Pineal Res. 2017; 63.

77. Perez Ortiz JM, Swerdlow RH. Mitochondrial dysfunction in Alzheimer's disease: Role in pathogenesis and novel therapeutic opportunities. Br J Pharmacol. 2019; 176: 3489-507.

78. Stefanova NA, Ershov NI, Maksimova KY, Muraleva NA, Tyumentsev MA, Kolosova NG. The Rat Prefrontal-Cortex Transcriptome: Effects of Aging and Sporadic Alzheimer's Disease-Like Pathology. J Gerontol A Biol Sci Med Sci. 2019; 74: 33-43.

79. Fu YJ, Xiong S, Lovell MA, Lynn BC. Quantitative proteomic analysis of mitochondria in aging PS-1 transgenic mice. Cell Mol Neurobiol. 2009; 29: 649-64.

80. Hauptmann S, Scherping I, Drose S, Brandt U, Schulz KL, Jendrach M, et al. Mitochondrial dysfunction: an early event in Alzheimer pathology accumulates with age in AD transgenic mice. Neurobiol Aging. 2009; 30: 1574-86.

81. Rudnitskaya EA, Muraleva NA, Maksimova KY, Kiseleva E, Kolosova NG, Stefanova NA. Melatonin Attenuates Memory Impairment, Amyloid-beta Accumulation, and Neurodegeneration in a Rat Model of Sporadic Alzheimer's Disease. J Alzheimers Dis. 2015; 47: 103-16.

82. Stefanova NA, Maksimova KY, Kiseleva E, Rudnitskaya EA, Muraleva NA, Kolosova NG. Melatonin attenuates impairments of structural hippocampal neuroplasticity in OXYS rats during active progression of Alzheimer's disease-like pathology. J Pineal Res. 2015; 59: 163-77.

83. Galano A, Tan DX, Reiter RJ. On the free radical scavenging activities of melatonin's metabolites, AFMK and AMK. J Pineal Res. 2013; 54: 245-57.

84. Hardeland R, Tan DX, Reiter RJ. Kynuramines, metabolites of melatonin and other indoles: the resurrection of an almost forgotten class of biogenic amines. J Pineal Res. 2009; 47: 109-26.

85. Dragicevic N, Copes N, O'Neal-Moffitt G, Jin J, Buzzeo R, Mamcarz M, et al. Melatonin treatment restores mitochondrial function in Alzheimer's mice: a mitochondrial protective role of melatonin membrane receptor signaling. J Pineal Res. 2011; 51: 75-86.

86. Pulimeno P, Mannic T, Sage D, Giovannoni L, Salmon P, Lemeille S, et al. Autonomous and self-sustained circadian oscillators displayed in human islet cells. Diabetologia. 2013; 56: 497-507.

87. Lee J, Ma K, Moulik M, Yechoor V. Untimely oxidative stress in beta-cells leads to diabetes - Role of circadian clock in beta-cell function. Free Radic Biol Med. 2018; 119: 69-74.

88. Liu K, Yu W, Wei W, Zhang X, Tian Y, Sherif M, et al. Melatonin reduces intramuscular fat deposition by promoting lipolysis and increasing mitochondrial function. J Lipid Res. 2019; 60: 767-82.

89. Ding M, Feng N, Tang D, Feng J, Li Z, Jia M, et al. Melatonin prevents Drp1-mediated mitochondrial fission in diabetic hearts through SIRT1-PGC1alpha pathway. J Pineal Res. 2018; 65: e12491.

90. Andersen LP, Werner MU, Rosenkilde MM, Harpsoe NG, Fuglsang H, Rosenberg J, et al. Pharmacokinetics of oral and intravenous melatonin in healthy volunteers. BMC Pharmacol Toxicol. 2016; 17: 8.

91. Harpsoe NG, Andersen LP, Gogenur I, Rosenberg J. Clinical pharmacokinetics of melatonin: a systematic review. Eur J Clin Pharmacol. 2015; 71: 901-9.

92. Flo A, Cambras T, Diez-Noguera A, Calpena A. Melatonin pharmacokinetics after transdermal administration changes according to the time of the day. Eur J Pharm Sci. 2017; 96: 164-70.

93. Zhang S, Wang P, Ren L, Hu C, Bi J. Protective effect of melatonin on soluble A $31-42$-induced memory impairment, astrogliosis, and synaptic dysfunction via the Musashi1/Notch1/Hes1 signaling pathway in the rat hippocampus. Alzheimer's research \& therapy. 2016; 8: 40.

94. Hu C, Wang P, Zhang S, Ren L, Lv Y, Yin R, et al. Neuroprotective effect of melatonin on soluble $A \beta(1-42)$-induced cortical neurodegeneration via Reelin-Dab1 signaling pathway. Neurological research. 2017; 39: 621-31.

95. Gong $\mathrm{YH}$, Hua $\mathrm{N}$, Zang $\mathrm{X}$, Huang $\mathrm{T}$, He L. Melatonin ameliorates $\mathrm{A} \beta(1-42)$-induced Alzheimer's cognitive deficits in mouse model. The Journal of pharmacy and pharmacology. 2018; 70: 70-80.

96. Chen BH, Park JH, Kim DW, Park J, Choi SY, Kim IH, et al. Melatonin Improves Cognitive Deficits via Restoration of Cholinergic Dysfunction in a Mouse Model of Scopolamine-Induced Amnesia. ACS chemical neuroscience. 2018; 9: 2016-24.

97. Chen BH, Park JH, Lee TK, Song M, Kim H, Lee JC, et al. Melatonin attenuates scopolamine-induced cognitive impairment via protecting against demyelination through BDNF-TrkB signaling in the mouse dentate gyrus. Chemico-biological interactions. 2018; 285: 8-13.
98. Muhammad T, Ali T, Ikram M, Khan A, Alam SI, Kim MO. Melatonin Rescue Oxidative Stress-Mediated Neuroinflammation/ Neurodegeneration and Memory Impairment in Scopolamine-Induced Amnesia Mice Model. J Neuroimmune Pharmacol. 2019; 14: 278-94.

99. Peng C, Hong X, Chen W, Zhang H, Tan L, Wang X, et al. Melatonin ameliorates amygdala-dependent emotional memory deficits in Tg2576 mice by up-regulating the CREB/c-Fos pathway. Neurosci Lett. 2017; 638: 76-82.

100. Pappolla MA, Matsubara E, Vidal R, Pacheco-Quinto J, Poeggeler B, Zagorski $M$, et al. Melatonin Treatment Enhances A $\beta$ Lymphatic Clearance in a Transgenic Mouse Model of Amyloidosis. Current Alzheimer research. 2018; 15: 637-42.

101. Corpas R, Griñán-Ferré C, Palomera-Ávalos V, Porquet D, García de Frutos P, Franciscato Cozzolino SM, et al. Melatonin induces mechanisms of brain resilience against neurodegeneration. J Pineal Res. 2018; 65: e12515

102. Jürgenson M, Zharkovskaja T, Noortoots A, Morozova M, Beniashvili A, Zapolski $\mathrm{M}$, et al. Effects of the drug combination memantine and melatonin on impaired memory and brain neuronal deficits in an amyloid-predominant mouse model of Alzheimer's disease. The Journal of pharmacy and pharmacology. 2019; 71: 1695-705.

103. Rong K, Zheng H, Yang R, Liu X, Li L, Chen N, et al. Melatonin and its metabolite $\mathrm{N}(1)$-acetyl-N(1)-formyl-5-methoxykynuramine improve learning and memory impairment related to Alzheimer's disease in rats. Journal of biochemical and molecular toxicology. 2020; 34: e22430.

104. Kamsrijai U, Wongchitrat P, Nopparat C, Satayavivad J, Govitrapong P. Melatonin attenuates streptozotocin-induced Alzheimer-like features in hyperglycemic rats. Neurochem Int. 2020; 132: 104601.

105. Jenwitheesuk A, Boontem P, Wongchitrat P, Tocharus J, Mukda S, Govitrapong P. Melatonin regulates the aging mouse hippocampal homeostasis via the sirtuin1-FOXO1 pathway. EXCLI journal. 2017; 16: 340-53.

106. Bogush M, Heldt NA, Persidsky Y. Blood Brain Barrier Injury in Diabetes: Unrecognized Effects on Brain and Cognition. J Neuroimmune Pharmacol. 2017; 12: 593-601.

107. Salameh TS, Mortell WG, Logsdon AF, Butterfield DA, Banks WA Disruption of the hippocampal and hypothalamic blood-brain barrier in a diet-induced obese model of type II diabetes: prevention and treatment by the mitochondrial carbonic anhydrase inhibitor, topiramate. Fluids Barriers CNS. 2019; 16: 1.

108. Bernard M, Guerlotte J, Greve P, Grechez-Cassiau A, Iuvone MP, Zatz $\mathrm{M}$, et al. Melatonin synthesis pathway: circadian regulation of the genes encoding the key enzymes in the chicken pineal gland and retina. Reprod Nutr Dev. 1999; 39: 325-34.

109. Zlotos DP, Jockers R, Cecon E, Rivara S, Witt-Enderby PA. MT1 and MT2 melatonin receptors: ligands, models, oligomers, and therapeutic potential. J Med Chem. 2014; 57: 3161-85.

110. Balmik AA, Chinnathambi S. Multi-Faceted Role of Melatonin in Neuroprotection and Amelioration of Tau Aggregates in Alzheimer's Disease. J Alzheimers Dis. 2018; 62: 1481-93.

111. Das R, Balmik AA, Chinnathambi S. Melatonin Reduces GSK3beta-Mediated Tau Phosphorylation, Enhances Nrf2 Nuclear Translocation and Anti-Inflammation. ASN Neuro. 2020; 12: 1759091420981204.

112. Shin Y, Choi SH, Kim E, Bylykbashi E, Kim JA, Chung S, et al. Blood-Brain Barrier Dysfunction in a 3D In Vitro Model of Alzheimer's Disease. Adv Sci (Weinh). 2019; 6: 1900962.

113. Huber JD, VanGilder RL, Houser KA. Streptozotocin-induced diabetes progressively increases blood-brain barrier permeability in specific brain regions in rats. Am J Physiol Heart Circ Physiol. 2006; 291: H2660-8.

114. Banks WA. Blood-brain barrier transport of cytokines: a mechanism for neuropathology. Curr Pharm Des. 2005; 11: 973-84.

115. Alluri H, Wilson RL, Anasooya Shaji C, Wiggins-Dohlvik K, Patel S, Liu $Y$, et al. Melatonin Preserves Blood-Brain Barrier Integrity and Permeability via Matrix Metalloproteinase-9 Inhibition. PLoS One. 2016; 11: e0154427.

116. Jumnongprakhon $\mathrm{P}$, Govitrapong $\mathrm{P}$, Tocharus $\mathrm{C}$, Tocharus J. Inhibitory effect of melatonin on cerebral endothelial cells dysfunction induced by methamphetamine via NADPH oxidase-2. Brain Res. 2016; 1650: 84-92.

117. Alzoubi KH, Mayyas FA, Mahafzah R, Khabour OF. Melatonin prevents memory impairment induced by high-fat diet: Role of oxidative stress. Behav Brain Res. 2018; 336: 93-8.

118. Pratico D, Uryu K, Leight S, Trojanoswki JQ, Lee VM. Increased lipid peroxidation precedes amyloid plaque formation in an animal model of Alzheimer amyloidosis. J Neurosci. 2001; 21: 4183-7.

119. Singh M, Jadhav HR. Melatonin: functions and ligands. Drug Discov Today. 2014; 19: 1410-8 
120. Xu J, Gao H, Zhang L, Rong S, Yang W, Ma C, et al. Melatonin alleviates cognition impairment by antagonizing brain insulin resistance in aged rats fed a high-fat diet. J Pineal Res. 2019; 67: e12584.

121. Gitto E, Aversa S, Salpietro CD, Barberi I, Arrigo T, Trimarchi G, et al. Pain in neonatal intensive care: role of melatonin as an analgesic antioxidant. J Pineal Res. 2012; 52: 291-5.

122. Wei S, Smits MG, Tang X, Kuang L, Meng H, Ni S, et al. Efficacy and safety of melatonin for sleep onset insomnia in children and adolescents: a meta-analysis of randomized controlled trials. Sleep Med. 2020; 68: 1-8.

123. Jain SV, Horn PS, Simakajornboon N, Beebe DW, Holland K, Byars AW, et al. Melatonin improves sleep in children with epilepsy: a randomized, double-blind, crossover study. Sleep Med. 2015; 16: 637-44.

124. Reiter RJ. The pineal and its hormones in the control of reproduction in mammals. Endocr Rev. 1980; 1: 109-31.

125. Yellon SM, Foster DL. Melatonin rhythms time photoperiod-induced puberty in the female lamb. Endocrinology. 1986; 119: 44-9.

126. Andersen LP, Gogenur I, Rosenberg J, Reiter RJ. The Safety of Melatonin in Humans. Clin Drug Investig. 2016; 36: 169-75.

127. Pourhanifeh MH, Hosseinzadeh A, Dehdashtian E, Hemati K, Mehrzadi S. Melatonin: new insights on its therapeutic properties in diabetic complications. Diabetol Metab Syndr. 2020; 12: 30.

128. Challet E. The circadian regulation of food intake. Nat Rev Endocrinol. 2019; 15: 393-405 